\title{
Lithiation and Delithiation Properties of Silicide/Si Composite Alloy Electrodes Prepared by Rapid Quenching Method
}

\author{
Yuta KIMURA, ${ }^{a, *}$ Yasuhiro DOMI, ${ }^{\mathrm{b}}$ Hiroyuki USUI, ${ }^{\mathrm{b}}$ and Hiroki SAKAGUCHI ${ }^{\mathrm{b}}$ \\ a Daido Steel Co., Ltd., 2-30 Daido-cho, Minami-ku, Nagoya, Aichi 457-8545, Japan \\ b Department of Chemistry and Biotechnology, Graduate School of Engineering, Tottori University, \\ 4-101 Koyama-cho Minami, Tottori 680-8552, Japan \\ *Corresponding author: y-kimura@ek.daido.co.jp
}

\section{ABSTRACT}

Rapid quenching is one of the methods for preparing silicide/Si composite alloy as an active material for negative electrode in lithium-ion batteries. In this study, we focused on the method's control over the positional relation between the Si and silicide phase by changing the additive elements. Various Si-alloys and the relationship between their lithiation and delithiation properties and their arrangement was investigated.

(c) The Author(s) 2020. Published by ECSJ. This is an open access article distributed under the terms of the Creative Commons Attribution 4.0 License (CC BY, http://creativecommons.org/licenses/by/4.0/), which permits unrestricted reuse of the work in any medium provided the original work is properly cited. [DOI: 10.5796/electrochemistry.20-00039]. Uploading "PDF file created by publishers" to institutional repositories or public websites is not permitted by the copyright license agreement.

Keywords : Lithium-ion Battery, Negative Electrode, Si Alloy, Silicide

\section{Introduction}

Silicon ( $\mathrm{Si})$ is very attractive as a high capacity active material for negative electrode in lithium-ion batteries (LIBs) because of its theoretical capacity value of $3600 \mathrm{~mA} \mathrm{~h}^{-1}\left(\mathrm{Li}_{15} \mathrm{Si}_{4}\right) .{ }^{1-3}$ However, $\mathrm{Si}$ expands and contracts largely during lithiation (charge) and delithiation (discharge), respectively. ${ }^{4}$ The expansion ratio per $\mathrm{Si}$ atom corresponds to $380 \%$, which generates high stress and large strain in the active materials. The strain that accumulate during repeated charge-discharge cycling causes collapse and pulverization. Consequently, Si electrode cannot exhibit sufficient cyclic stability.

Compositing transition metal silicide and $\mathrm{Si}$ is one of the effective methods for improving the cyclic stability of the $\mathrm{Si}$ electrode. ${ }^{5}$ We have previously reported that the following four kinds of properties are essential for compositing phases with $\mathrm{Si}:^{5-10}$

1) Mechanical properties suitable for the relaxation of the stress from $\mathrm{Si}$

2) High electronic conductivity

3) Moderate reactivity with $\mathrm{Li}^{+}$

4) High thermodynamic stability

Many studies utilizing a mechanical alloying method with planetary ball mill have been reported for preparing silicide/Si composite alloys. ${ }^{6,11-13}$ Conversely, rapid quenching method can also be used for producing Si-alloys. ${ }^{14,15}$ We focused on this method's control over the arrangement of Si and silicide phases, by changing the additive elements. Figure 1 presents a schematic illustration of the structural formation of Si-alloy by rapid quenching. While the crystallizing of $\mathrm{Si}$ is the initial phase from the molten Si-alloy (Fig. 1, Pattern 1), silicide phase forms around the Si phase. In contrast, in the case of crystallizing silicide phase as the initial phase (Fig. 1, Pattern 2), Si phase forms around the silicide phase. Formation of Pattern 1 or Pattern 2 is dependent on the elements and the amount of the additives present. In this study, we prepared various binary Si-alloys, and evaluated the influence of the arrangements between the Si phase and silicide phase on the electrochemical performance of LIBs.

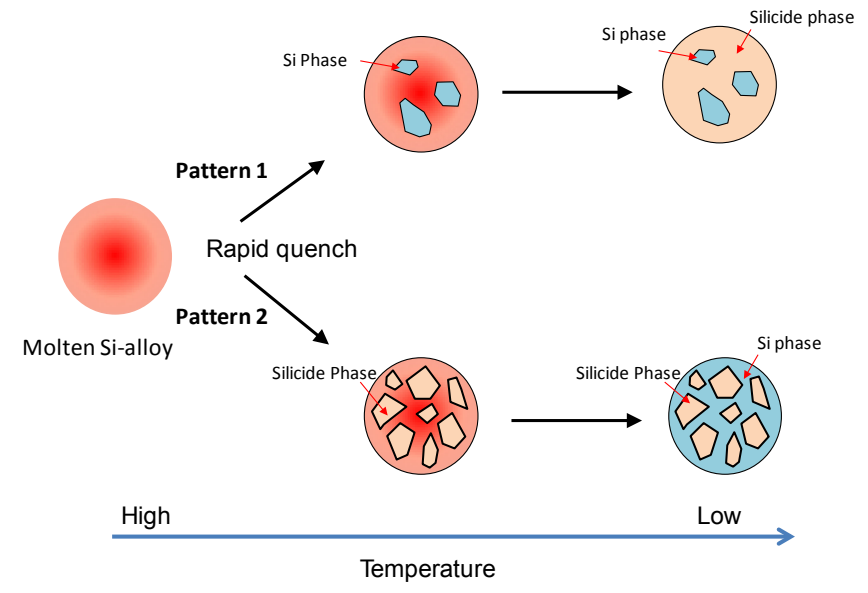

Figure 1. Schematic illustration of the phase-structure formation by rapid quenching method.

\section{Experimental Method}

\subsection{Selection of additive element}

Iron $(\mathrm{Fe})$, Copper $(\mathrm{Cu})$, and Cobalt $(\mathrm{Co})$ were selected as the additives for making $\mathrm{Si}$ in the initial phase (Pattern 1) with reference to binary phase diagrams. Further, Zirconium (Zr) and Titanium (Ti) were selected for making silicide in the initial phase (Pattern 2). The corresponding amount of additives was determined by the ratio of the Si phase to silicide phase as 33:67 mass\%. Table 1 lists the contents and the silicide phase of synthesized Si-alloys.

\subsection{Preparation of Si-alloy ribbon by rapid quenching}

Si-alloys were prepared by rapid quenching. First, Si-alloy ingots were prepared in a button arc furnace. Next, the ingot was melted at approximately $1773 \mathrm{~K}$ in an induction furnace. After melting, the molten Si-alloy was dropped on a $\mathrm{Cu}$ roll at a rotating speed of $40 \mathrm{~m} / \mathrm{s}$. The molten Si-alloy was thus quenched and Si-alloy ribbons 
Table 1. Contents and silicide phase of synthesized Si-alloys.

\begin{tabular}{|c|c|c|c|c|c|c|}
\hline \multirow{2}{*}{$\begin{array}{l}\text { Alloy } \\
\text { type }\end{array}$} & \multirow{2}{*}{$\begin{array}{l}\text { Silicide } \\
\text { phase }\end{array}$} & \multicolumn{2}{|c|}{ Contents (mass\%) } & \multicolumn{2}{|c|}{ Phase ratio (mass\%) } & \multirow{2}{*}{$\begin{array}{l}\text { Initial } \\
\text { phase }\end{array}$} \\
\hline & & $\mathrm{Si}$ & $\mathrm{X}$ & $\mathrm{Si}$ & Silicide & \\
\hline $\mathrm{Si}-\mathrm{Fe}$ & {$\left[\mathrm{FeSi}_{2}\right]$} & 66.5 & 33.5 & & & {$[\mathrm{Si}]$} \\
\hline $\mathrm{Si}-\mathrm{Cu}$ & {$\left[\mathrm{Cu}_{3} \mathrm{Si}\right]$} & 41.0 & 59.0 & & & {$[\mathrm{Si}]$} \\
\hline $\mathrm{Si}-\mathrm{Co}$ & {$\left[\mathrm{CoSi}_{2}\right]$} & 65.8 & 34.2 & 33 & 67 & {$[\mathrm{Si}]$} \\
\hline $\mathrm{Si}-\mathrm{Zr}$ & {$\left[\mathrm{ZrSi}_{2}\right]$} & 58.6 & 41.4 & & & {$\left[\mathrm{ZrSi}_{2}\right]$} \\
\hline $\mathrm{Si}-\mathrm{Ti}$ & {$\left[\mathrm{TiSi}_{2}\right]$} & 69.2 & 30.8 & & & {$\left[\mathrm{TiSi}_{2}\right]$} \\
\hline
\end{tabular}

were prepared. The thickness of these ribbons was approximately $20 \mu \mathrm{m}$.

\subsection{Cross-sectional observation and FE-EPMA analysis of Si- alloy ribbons}

Si-alloy ribbons were placed in a Bakelite resin. Samples for the cross-sectional observation were prepared using mechanical polishing. The cross-sectional observation was performed using a fieldemission scanning electron microscope (FE-SEM, SU6600, Hitachi High-Technologies Corporation). The accelerating voltage was set at $15 \mathrm{kV}$ and the magnification was $5000 \times$. Field emission-electron probe microanalysis (FE-EPMA, JXA-8500F, JEOL, Co., Ltd.) was used for detecting the position of $\mathrm{Si}$ and additive elements. The accelerating voltage was $15 \mathrm{kV}$, irradiation current was $50 \mathrm{nA}$, and magnification was $5000 \times$.

\subsection{Cell assembly and electrochemical measurement}

Si-alloys were pulverized by hand milling and classified as $<25 \mu \mathrm{m}$. Active material (Si-alloy powders), conductive agent (Ketjen black), and polyamic acid binder (Dreambond, I. S. T. Corporation) were mixed in the ratio of 85:5:10 (wt\%). The mixture was diluted using 1-methyl-2-pyrrolidone for preparing slurry. We painted the slurry on a SUS316L foil (thickness: $20 \mu \mathrm{m}$ ) using a doctor blade with a thickness of $50 \mu \mathrm{m}$. SUS316L foil was used as current collector to suppress deformation during charge-discharge cycle. The electrode was then dried at $343 \mathrm{~K}$ for $>30 \mathrm{~min}$. We heated the electrode in vacuum at $573 \mathrm{~K}$ for $1 \mathrm{~h}$ for polyimidation. The electrode thickness after heating was approximately $30 \mu \mathrm{m}$.

A 2032-type coin cell was used for evaluating the electrochemical performance of the Si-alloy electrode. The coin cell comprised of a Si-alloy electrode as its working electrode, a glass fiber filter as the separator, and a $\mathrm{Li}$ metal sheet (thickness: $1 \mathrm{~mm}$, diameter: $12 \mathrm{~mm}$ ) as the counter electrode. $1 \mathrm{M}$ lithium hexafluorophosphate $\left(\mathrm{LiPF}_{6}\right)$ dissolved in ethylene carbonate $(\mathrm{EC})$ : diethyl carbonate (DEC) (EC: $\mathrm{DEC}=1: 1 \mathrm{vol} \%$ ) was employed as the electrolyte. The cell was assembled in an open dry chamber (HWR-60AR, DAIKIN INDUSTRIES Ltd.) maintaining its dew point at $<-70^{\circ} \mathrm{C}$.

The charge-discharge cycle test was performed with an electrochemical measurement system (TOSCAT3100, TOYO SYSTEM Co., LTD.) in the potential range of $0.002-1.000 \mathrm{~V}$ vs. $\mathrm{Li}^{+} / \mathrm{Li}$ at $298 \mathrm{~K}$. The current was set at $0.2 \mathrm{~mA}$ in the first cycle to measure accurate initial discharge capacity. After the second cycle, the current density was set to about $0.3 \mathrm{Ag}(\mathrm{Si}+\text { silicide })^{-1}$.

\section{Results and Discussion}

\subsection{Characterization}

We confirmed that the Si-alloys composed only of Si and silicide phases using X-ray diffraction (XRD) technique. Figure 2 shows the FE-EPMA analysis results of the cross-section of $\mathrm{Si}-\mathrm{Fe}$ alloy and $\mathrm{Si}-\mathrm{Zr}$ alloy ribbons. The elemental mapping result (Fig. 2(a)) confirmed that the black phase is $\mathrm{Si}$ and the white phase is Ironsilicide $\left(\mathrm{FeSi}_{2}\right)$. Hence, the silicide phase surrounded the Si phase in $\mathrm{Si}-\mathrm{Fe}$ alloy. Furthermore, the black phase formed around the white phase in $\mathrm{Si}-\mathrm{Zr}$ alloy (Fig. 2(b)), that is, $\mathrm{Si}-\mathrm{Zr}$ alloy is that Si phase surrounded silicide phase $\left(\mathrm{ZrSi}_{2}\right)$.

Figure 3 shows the cross-sectional SEM images of Si-alloy ribbons. From the positional relation of black phase (Si phase) and white phase (silicide phase) of $\mathrm{Si}-\mathrm{Fe}, \mathrm{Si}-\mathrm{Cu}$ and $\mathrm{Si}-\mathrm{Co}$ alloys, we can see that $\mathrm{Si}$ crystallized as the initial phase and silicide phase formed around the $\mathrm{Si}$ phase. For $\mathrm{Si}-\mathrm{Zr}$ and $\mathrm{Si}-\mathrm{Ti}$ alloys, silicide phase crystallized as the initial phase and Si phase formed around the silicide phase. Thus, by varying the additives, we could prepare various Si-alloys that differ in the positional relationship with respect to $\mathrm{Si}$ and silicide phases.

\subsection{Charge-discharge cycle test of Si-alloy electrodes}

Figure 4 shows the results of the cycle test of Si-alloy electrodes. The discharge capacity of all Si-alloys decreased significantly during the first and second cycles. This is because of the current density in the first cycle $\left(0.2 \mathrm{~mA}\right.$ c.c., $\left.0.075 \mathrm{Ag}(\mathrm{Si}+\text { silicide })^{-1}\right)$ is lower than that in the second cycle $\left(0.8 \mathrm{~mA}\right.$ c.c., $\left.0.3 \mathrm{Ag}(\mathrm{Si}+\text { silicide })^{-1}\right)$ to measure the accurate initial discharge capacity of Si-alloy electrode. A decrease in the discharge capacity of $\mathrm{Si}-\mathrm{Fe}$ and $\mathrm{Si}-\mathrm{Zr}$ alloy electrodes from the first to second cycle was smaller than that of other $\mathrm{Si}-\mathrm{Cu}, \mathrm{Si}-\mathrm{Co}$, and $\mathrm{Si}-\mathrm{Ti}$ electrodes, which indicates that the rate capability of the former two electrodes is superior to others. Additionally, initial discharge capacity of $\mathrm{Si}-\mathrm{Zr}$, Si-Co, and $\mathrm{Si}-\mathrm{Ti}$ electrodes was higher than that of others.

After the second cycle, discharge capacity gradually decreased with a progressing cycle. We infer that the reduction of capacity is due to the gradual collapse of Si-alloy because of repeated chargedischarge and the loss of conduction path of Li-ion/electron. We can
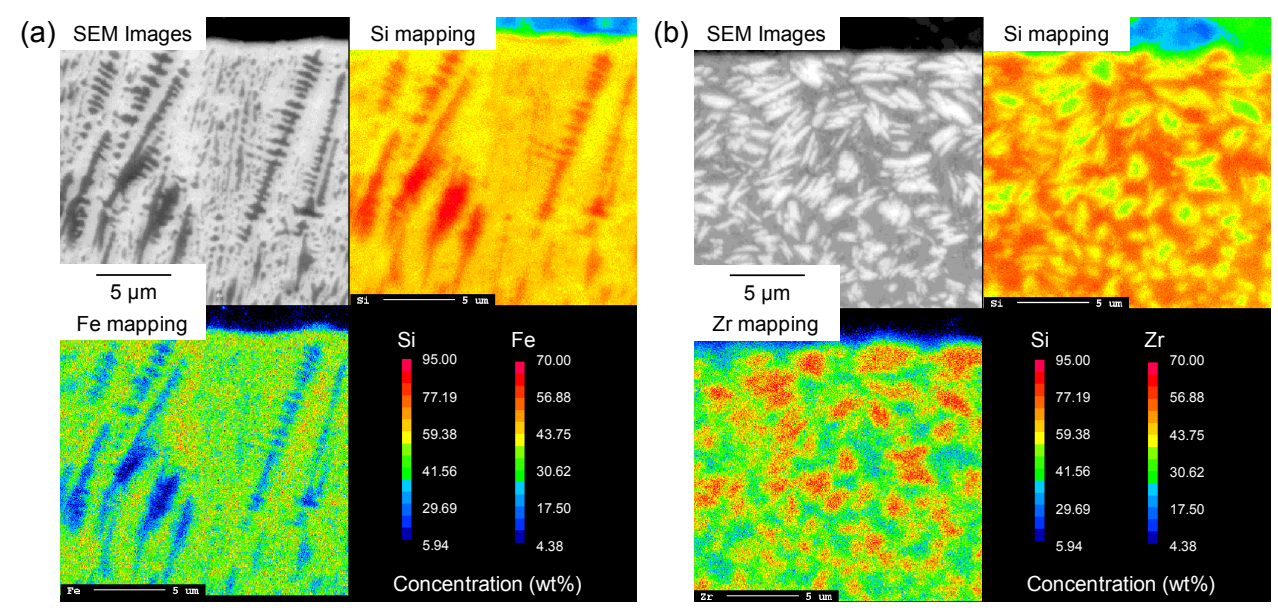

Figure 2. Results of FE-EPMA of prepared (a) Si-Fe alloy and (b) $\mathrm{Si}-\mathrm{Zr}$ alloy on a $5 \mu \mathrm{m}$ scale bar. 


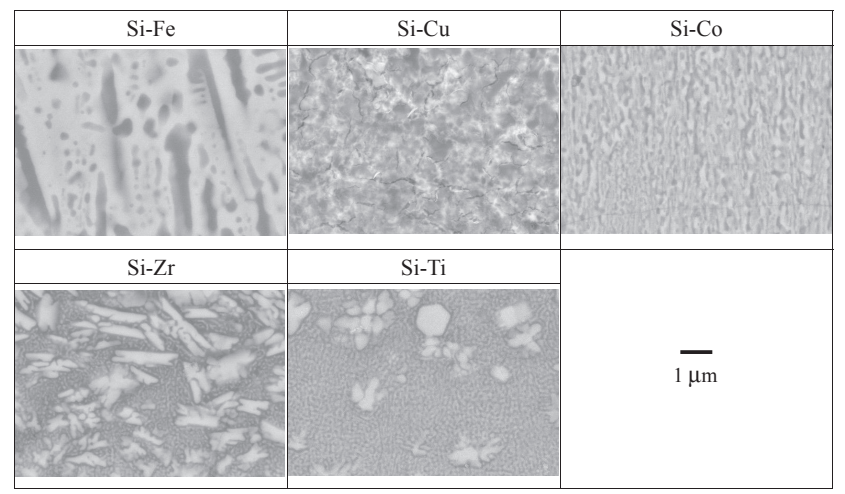

Figure 3. Cross-sectional SEM images of prepared Si-alloy on a $1 \mu \mathrm{m}$ scale bar.

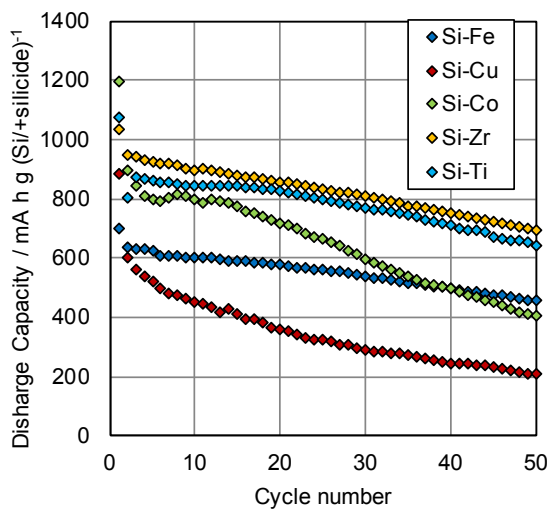

Figure 4. Charge-discharge cycling performances of Si-alloys.

\begin{tabular}{|c|c|c|c|c|c|}
\hline & $\mathrm{Si}-\mathrm{Fe}$ & $\mathrm{Si}-\mathrm{Cu}$ & $\mathrm{Si}-\mathrm{Co}$ & $\mathrm{Si}-\mathrm{Zr}$ & Si-Ti \\
\hline \multicolumn{6}{|l|}{$\begin{array}{l}\text { Before } \\
\text { charge }\end{array}$} \\
\hline & 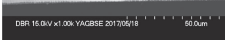 & 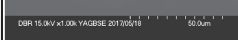 & 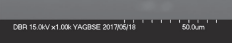 & 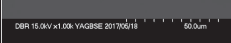 & 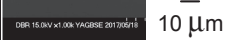 \\
\hline After & & & & & 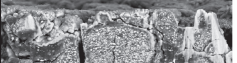 \\
\hline & 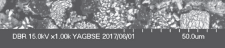 & contase & sx anoweti & Entar. & \\
\hline
\end{tabular}

Figure 5. Cross-sectional SEM images of Si-alloy electrodes before and after the 50 th cycle on a $10 \mu \mathrm{m}$ scale bar.

confirm that $\mathrm{Si}-\mathrm{Zr}$ and $\mathrm{Si}-\mathrm{Ti}$ alloy electrodes exhibit high initial capacity and good cycle stability. It is considered that four properties of silicide (electrical resistivity, reactivity with $\mathrm{Li}^{+}$, thermodynamic stability, and mechanical properties) influence on the electrochemical performance of the silicide/Si composite electrodes. ${ }^{5-10}$ In this study we founded that the arrangement of Si and silicide phases is likely to influence on the electrochemical performance of Si-alloy in addition to above silicide properties.

\subsection{Effect of the arrangement of Si and silicide phase on cycle stability}

Figure 5 shows the cross-sectional SEM images of Si-alloy electrodes before and after the 50th cycles. In $\mathrm{Si}-\mathrm{Cu}$ and $\mathrm{Si}-\mathrm{Co}$ alloys, there was a small electrode layer on the current collector because the electrode layer of those alloys reduced during rinsing of the electrode. Active material particles collapsed during the chargedischarge cycle and were exfoliated from the current collector. As the result, it was consider that the collapsed particles removed from the electrode during rinsing and the electrode layer became small. There was a space between electrode layer and current collector in $\mathrm{Si}-\mathrm{Cu}$ alloy. This space may be generated during polishing for sample preparation. Further, $\mathrm{Si}-\mathrm{Fe}$ alloy collapsed and was pulverized. Electrode thickness of Si-Fe alloy after the 50th cycle increased by a factor of approximately three compared to before charging. Si-Zr and $\mathrm{Si}-\mathrm{Ti}$ alloys maintained their particle shape. The expanding of electrode thickness was approximately 1.5 times, which was considerably smaller than that of $\mathrm{Si}-\mathrm{Fe}$ alloy. These results indicate that collapse of $\mathrm{Si}-\mathrm{Zr}$ and $\mathrm{Si}-\mathrm{Ti}$ alloys was suppressed during the charge-discharge cycle. We believe that the positional relation between the Si phase and the silicide phase was influential in this regard. In the $\mathrm{Si}-\mathrm{Fe}, \mathrm{Si}-\mathrm{Cu}$, and $\mathrm{Si}-\mathrm{Co}$ alloys (Fig. 1, Pattern 1), the silicide phase was subject to large stress due to the $\mathrm{Li}$ storage in the $\mathrm{Si}$ phase, which causes electrode expansion. As a result, Si-alloy collapsed and the electrode thickness increased. In the $\mathrm{Si}-\mathrm{Zr}$ and $\mathrm{Si}-\mathrm{Ti}$ alloys (Fig. 1, Pattern 2), the stress which the silicide phase received is small because $\mathrm{Si}$ phase can expand outward during Li storage. Consequently, the collapse of Si-alloy particle was suppressed and the cycle stability of Si-alloy improved.

\section{Conclusion}

We prepared various Si-alloys, whose structures were controlled by rapid quenching, and evaluated their electrochemical properties. Our results determined that the collapse of Si-alloy was suppressed and the cycle stability was improved by selecting additive elements (like $\mathrm{Zr}$ or $\mathrm{Ti}$ ) to locate the $\mathrm{Si}$ phase around the silicide phase.

\section{References}

1. M. S. Whittingham, Chem. Rev., 104, 4271 (2004).

2. M. N. Obrovac and L. Christensen, Electrochem. Solid-State Lett., 7, A93 (2004).

3. B. Key, M. Morcrette, J. M. Tarascon, and C. P. Grey, J. Am. Chem. Soc., 133, 503 (2011).

4. K. Ogata, E. Salager, C. J. Kerr, A. E. Fraser, C. Ducati, A. J. Morris, S. Hofmann, and C. P. Grey, Nat. Commun., 5, 3217 (2014).

5. T. Iida, T. Hirono, N. Shibamura, and H. Sakaguchi, Electrochemistry, 76, 644 (2008).

6. H. Sakaguchi, T. Iida, M. Itoh, N. Shibamura, and T. Hirono, IOP Conf. Series: Mater. Sci. Eng., 1, 012030 (2009).

7. H. Usui, H. Nishinami, T. Iida, and H. Sakaguchi, Electrochemistry, 78, 329 (2010).

8. H. Usui, K. Maebara, K. Nakai, and H. Sakaguchi, Int. J. Electrochem. Sci., 6, $2246(2011)$

9. Y. Domi, H. Usui, Y. Takemoto, K. Yamaguchi, and H. Sakaguchi, J. Phys. Chem. C, 120, 16333 (2016).

10. Y. Domi, H. Usui, Y. Takemoto, K. Yamaguchi, and H. Sakaguchi, Chem. Lett., 45, 1198 (2016).

11. Y. NuLi, B. Wang, J. Yang, X. Yuan, and Z. Ma, J. Power Sources, 153, 371 (2006).

12. G. Xiao, H. Xue, G. Cheng, and X. Bao, J. Chem. Eng. Chinese Universities, 20, 634 (2006).

13. S. Kawakami, H. Kaidou, Y. Akita, H. Munakata, and K. Kanamura, Electrochemistry, 83, 445 (2015).

14. M. S. Bae, K. Y. Sohn, and W. W. Park, Electron. Mater. Lett., 10, 795 (2014).

15. N. S. Nazer, R. V. Denys, H. F. Andersen, L. Arnberg, and V. A. Yartys, J. Alloys Compd., 718, 478 (2017). 